\title{
Cooperativas de catadores de resíduos e cadeias logísticas reversas: estudo de dois casos
}

\author{
Waste collectors cooperatives and reverse logistics networks: double case study \\ Francieli Aparecida de Almeida', Anna Paula Severo Viana², \\ Ágata Maitê Ritter ${ }^{3}$, Miguel Afonso Sellitto ${ }^{4}$ \\ ${ }^{123}$ Mestranda em Engenharia de Produção e Sistemas pelo PPGEPS UNISINOS - São Leopoldo, RS - Brasil \\ ${ }^{4}$ Professor e pesquisador do PPGEPS UNISINOS - São Leopoldo, RS - Brasil
}

\begin{abstract}
Resumo
O objetivo deste artigo foi analisar o funcionamento de duas cooperativas de catadores que fornecem resíduos processados que retornam a indústrias na cidade de São Leopoldo, RS. O método de pesquisa foi o estudo de caso em duas das seis cooperativas em operação na cidade. Foram consultados documentos das cooperativas e materiais produzidos pelo poder público municipal e realizadas observações não-participantes e entrevistas com os presidentes das cooperativas estudadas. Uma das cooperativas recebe apenas materiais da coleta seletiva, enquanto que a outra recebe toda a coleta domiciliar. A cooperativa que recebe apenas a coleta seletiva, apesar de ser mais recente e menos estruturada, oferece mais renda a seus cooperados. O material recuperado por ambas as cooperativas é vendido a intermediários que dão escala à operação e vendem à indústria como matéria-prima recuperada. Concluiu-se que o papel das cooperativas na cadeia reversa é o de recuperar materiais pós-consumo e atuar como abastecedor de matérias-primas da indústria. Adicionalmente, as cooperativas desempenham papel social junto a comunidades de baixa renda, por oferecerem alternativas de emprego e renda, e papel ambiental, por contribuir para a redução da pressão sobre aterros sanitários e incineração de resíduos sólidos urbanos.
\end{abstract}

Palavras-chave: Cooperativas de Catadores, Resíduos Sólidos, Logística Reversa, Reciclagem, Reciclagem, Aterro Sanitário.

\begin{abstract}
The objective of the article was to analyze the functioning of two cooperatives that provide processed waste required by industries in the city of São Leopoldo, RS. The research method was the double case study. Two out of the six cooperatives in operation in the city were studied. Documentation of the cooperative and produced by the municipal public authority were consulted, non-participant observations and interviews with the Presidents of cooperatives were made. One of the cooperatives receives only materials from selective collection, while the other receives the entire home collection. The cooperative that receives selected stuff, despite being more recent and less structured, provides more income to their members. The material recovered by both cooperatives is sold to intermediaries who give scale to the operation and sell to industry as recovered raw material. It was concluded that the role of cooperatives in the reverse chain is to retrieve post-consumer materials and act as a supplier of raw materials for industry. Additionally, cooperatives play social role to low-income communities, by providing jobs and income alternatives, and environmental role, by contributing to the reduction of pressure on landfills and incineration of municipal solid waste.
\end{abstract}

Keywords: Cooperatives, Solid Waste, Reverse Logistics, Recycling Landfills. 


\section{INTRODUÇÃO}

Recentemente, devido principalmente aos avanços tecnológicos observados, têm sido observadas a aquisição e o consumo de bens cada vez mais modernos e de vida útil cada vez mais curta. A necessidade que consumidores têm de constante atualização de seus bens, associada a ciclos de vida menores de produtos, tem levado a um comportamento de consumo que estimula as empresas a produzir mais itens, a modificar os projetos de produtos existentes e a lançar produtos que tornam obsoletos outros produtos, mesmo antes do fim do ciclo de vida (BORCHARDT et al., 2008). Em decorrência principalmente do comportamento do consumidor, mas também do crescimento da população urbana, tem aumentado a demanda por recursos naturais e energéticos, principalmente não-renováveis, e também a necessidade de instalações para destinação final dos resíduos sólidos urbanos (RSU) gerados pelo consumo das famílias e das indústrias (OLIVEIRA et al., 2012; ROCHA, 2012).

Um dos modos de tratar o problema da destinação final de resíduos sólidos é o campo de estudos conhecido por logística reversa. Para Adlmaier e Sellitto (2007), a logística reversa procura dar destinação ambientalmente amigável a resíduos sólidos gerados por atividades industriais ou domiciliares. Tal destinação inclui reaproveitamento, reciclagem, remanufatura, recondicionamento e descarte adequado de bens. Em síntese, é objetivo da logística reversa recuperar parte do valor original ainda remanescente no bem, se possível, de uma forma ambientalmente correta e socialmente justa (BARKER e ZABINSKY, 2011). Ao contrário da logística direta, que parte do ponto de produção, a logística reversa planeja e controla o fluxo de informações logísticas a partir do ponto de retorno (LEITE, 2009).

Um elemento presente em cadeias reversas de recuperação de valor de resíduos é a cooperativa de reciclagem. Cooperativas de reciclagem são associações de trabalhadores, geralmente oriundos de camadas mais vulneráveis da população que, apoiadas pelo poder público, coletam, recebem, separam, processam, embalam e retornam itens aos ciclos produtivos industriais. São exemplos de itens que retornam: vidros, papéis e papelões, recipientes metálicos (latas, latinhas, baldes), embalagens PET, entre outros. Tais cooperativas desempenham relevante papel, pois, além de reduzir o descarte inadequado de resíduos, reduzem a extração de novos recursos naturais e melhoram a situação de comunidades vulneráveis, pois oferecem a seus membros opção digna de emprego e renda (AQUINO et al., 2009).

A questão de pesquisa foi: Como cooperativas de catadores podem se inserir em cadeias logísticas reversas? O objetivo geral do artigo é analisar o funcionamento de duas cooperativas de catadores que fornecem resíduos processados que retornam a indústrias na cidade de São Leopoldo, RS. Os objetivos específicos foram: descrever o funcionamento de duas cooperativas de catadores; e apontar como as mesmas se relacionam com o programa de coleta seletiva e com o retorno de resíduos à indústria na cidade de São Leopoldo, RS. O método de pesquisa foi o estudo de caso duplo. As principais técnicas de pesquisa foram a entrevista, a observação não-participante e a análise documental.

O restante do artigo está organizado em: revisão, metodologia, resultados, discussão, e conclusões. Parte da pesquisa foi financiada pelo CNPq.

\section{RESÍDUOS SÓLIDOS URBANOS E LOGÍS- TICA REVERSA}

Resíduos sólidos urbanos (RSU) são gerados pela atividade industrial e comercial, pelo consumo das famílias e pelas atividades de varrição e capina de logradouros públicos (SANTIAGO e DIAS, 2012). Segundo a Associação Brasileira de Empresas de Limpeza Pública e Resíduos Especiais, a geração de RSU no Brasil tem registrado expressivo crescimento nos últimos anos, superando o crescimento populacional. De 2011 para 2012, o crescimento do RSU foi de 1,3\% e o da população foi de $0,9 \%$. A geração de RSU per capita cresceu $0,4 \%$, passando de 381,6 para 383,2 quilos por habitante por ano, o que dá mais de um quilo por dia por habitante. Tal característica origina-se diretamente da mudança de hábitos de consumo das famílias e do aumento da atividade industrial (ABRELPE, 2012).

A parte aproveitável dos RSU é coletada em atividades específicas de limpeza urbana, as chamadas coletas seletivas, e destinadas a algum tipo de recuperação de valor. A parte não aproveitável, porém, exige e sobrecarrega as estruturas municipais de destinação final (GEORG et al., 2009). A destinação final de RSU pode ser feita em vazadouros (também chamados de lixões), aterros controlados e aterros sanitários (VILLARES, 2009; MONTEIRO e ZVEIBIL, 2001). 
Em vazadouros, são despejados no solo aleatoriamente todo tipo de resíduos sólidos, sem proteção, o que pode incluir resíduos perigosos, resíduos de serviço de saúde (RSS) e outras formas danosas ao ambiente e à saúde. Vazadouros atraem atividade humana sujeita a alto risco e alta degradação, proliferando vetores de doenças, convivência com animais e diversas formas de ataques ambientais, tais como poluição do solo, do lençol freático, e atmosférica. Aterros controlados são formas inadequadas de destinação final, acarretando prejuízos ao ambiente e à saúde pública (FRÉSCA, 2007; ROCHA, 2012). Se bem que não causem danos ou riscos à saúde pública, ainda produzem poluição, pois não há tratamento do chorume nem queima do biogás originado da decomposição dos resíduos. Confinam-se os resíduos sólidos cobrindo-os com manta plástica impermeável ao fim da jornada de trabalho, porém não há impermeabilização da base. A maioria, apenas, constrói uma cerca viva e compacta os resíduos diariamente. Aterros sanitários são obras com critérios de engenharia, incluindo instalações confinadas, em camadas cobertas com material inerte, impermeabilização do solo, e coleta e tratamento de chorume e biogás, impossibilitando a contaminação do solo e seguindo normas específicas de segurança. A base do aterro sanitário deve ser formada por um sistema de drenagem de chorume, sobre solo compactado para evitar contaminação do lençol freático. Também deve conter um sistema de drenagem de biogás, que pode ser queimado ou usado para geração de energia. A cobertura deve incluir um sistema de drenagem de águas pluviais. $\mathrm{O}$ aterro sanitário deve ter sistema de monitoramento ambiental. Ao final de sua vida útil, é necessário recuperar o terreno (JACOBI, 2003; LEITE et al., 2004; LEITE, 2006; CELERE et al., 2007; PFEIFER, 2001).

Os principais compostos gerados pelos acúmulos de resíduos são o biogás e o chorume. O biogás resulta da biodegradação anaeróbia de matérias orgânicas, como as depositadas em aterros. Seus principais constituintes são o metano e o dióxido de carbono, mas outros gases, como sulfeto de hidrogênio, nitrogênio, hidrogênio e monóxido de carbono, também podem estar presentes. A emissão do biogás causa danos à vegetação, gera odores desagradáveis, oferece risco de explosão e contribui para o efeito estufa. O biogás pode ser usado para geração de energia ou deve ser simplesmente queimado (SOUZA et al., 2010). O chorume é um composto líquido que surge da decomposição dos resíduos depositados no aterro.
Combina água, gorduras, ácidos e componentes lixiviados, formando um composto agressivo que exige tratamento específico, sob pena de ataque às reservas de água superficiais e subterrâneas e solo (NAIME et al., 2013).

A Pesquisa Nacional de Saneamento Básico (PNSB/IBGE), feita no ano 2000, apontou que $63,6 \%$ dos municípios brasileiros utilizavam na época vazadouros como forma de disposição dos resíduos sólidos urbanos, contra $18,4 \%$ que utilizava aterros controlados e $13,8 \%$ aterros sanitários (MESQUITA JUNIOR, 2007). Em 2008, o percentual de municípios que destinavam seus RSU a vazadouros foi de $50,8 \%$, enquanto que os que utilizavam aterros sanitários foi de 27,7\% (IBGE, 2010). A mesma pesquisa informou que na época apenas $7 \%$ dos municípios tinham programas de coleta seletiva (SANTIAGO e DIAS, 2012). A pesquisa da ABRELPE de 2012 informa que 57,98\% do RSU brasileiro tiveram destino adequado e que cerca de $60 \%$ dos municípios registraram algum tipo de iniciativa de coleta seletiva de RSU em 2012 (ABRELPE, 2012).

A Política Nacional de Resíduos Sólidos (PNRS), regulamentada em 2010, tornou obrigatória a coleta seletiva em todas as cidades do país, com responsabilidade compartilhada entre órgãos públicos, empresas e sociedade: todos devem assegurar que a lei seja cumprida. Foi dado prazo de quatro anos para a erradicação dos vazadouros nas cidades. Com isso, valorizou-se o papel das cooperativas de reciclagem, pois estas, ao reduzirem a quantidade de material a ser disposto, contribuem diretamente para o pleno cumprimento da lei.

No capítulo III, artigo 36 da PNRS consta que o poder público deve priorizar a organização, o funcionamento e a contratação de cooperativas ou de outras formas de associação formal de catadores formadas por pessoas físicas de baixa renda, ou seja, as cooperativas devem ser apoiadas pelas prefeituras para pleno funcionamento (ANDRADE et al., 2010; MACHADO, 2012). Também é papel das prefeituras envolver a população para que separem os resíduos recuperáveis, contribuindo para a sustentabilidade das cooperativas e associações de catadores (HIRAMA e SILVA, 2009; GONÇALVES-DIAS, 2006).

Com a PNRS, aumentou a importância dos catadores e recicladores, autônomos ou cooperativados. A PNRS reconhece o resíduo sólido recuperável como bem econômico e de valor social, gerador de trabalho e renda e promotor de cidadania (PEREIRA NETO, 2011). A segregação de resíduos é necessária, pois estes podem ser 
utilizados como matéria-prima para novos produtos, além de reduzir a quantidade de material destinada aos aterros, aumentando sua vida útil (COSTA et al., 2012). Dados do Compromisso Empresarial para a Reciclagem (CEMPRE) no Brasil mostram que o número de municípios com coleta seletiva passou de $91 \mathrm{em} 1984$ para $405 \mathrm{em}$ 2008 , tendo neste ano atingido mais de 26 milhões de brasileiros. Como a coleta seletiva se relaciona diretamente com cooperativas de catadores, mais de 200 mil pessoas em todo o Brasil têm garantida a sobrevivência com a coleta e separação de RSU (CEMPRE, 2008).

Em alguns grupos de catadores, há más condições de higiene e segurança. Em outros, principalmente nas maiores cooperativas, há gestão do negócio, maquinaria industrial, e equipamentos de segurança, o que confere mais segurança e dignidade ao trabalho. De modo geral, todos têm reconhecimento público pelo papel que exercem como agente de limpeza municipal e na conservação dos recursos naturais (MORAES et al., 2006; MORAES, 2011; BELTRAME et al., 2012).

\section{I Logística e cadeias reversas}

A PNRS também reconhece o papel da logística reversa na gestão integrada dos RSU (PEREIRA NETO, 2011).

Atividades de logística reversa incluem a reintrodução de produtos e materiais retornados após a venda ou consumo na cadeia produtiva, para que possam ser reaproveitados (CHAVES, 2005). A logística reversa tem atraído a atenção de pesquisadores e praticantes devido ao seu potencial de recuperação do valor de produtos já utilizados. Adicionalmente, atendimento a legislações, criação de imagem corporativa favorável e assunção de responsabilidades socioambientais têm sido estimuladores de práticas reversas na indústria. Uma decorrência positiva de práticas reversas foi o aumento da vida útil de aterros e a diminuição da incineração como prática de destinação final (SARKIS et al., 2010; POKHAREL e MUTHA, 2009).

A logística reversa é parte integrante da gestão da cadeia de suprimentos, preocupando-se com o que acontece nas etapas de pós-venda e pós-consumo dos bens distribuídos pela cadeia (LEITE, 2009). Para Roger et al. (2012), a logística reversa vem sendo definida como o processo de planejar, implementar e controlar o fluxo de retorno de materiais já vendidos e não usados ou já consumidos, de forma eficiente e rentável, com o propósito de recuperar uma parte do seu valor, ainda existente, ou ao menos promover um descarte ambientalmente correto. De acordo com Ballou (2005) para muitas empresas também existe um canal reverso para ser gerenciado, pois, a vida de um produto não se encerra quando chega ao cliente ou quando é consumido: ela só se encerra quando acontece o descarte final. Dado isso, o canal reverso deve estar dentro das diretrizes do planejamento e controle logístico de uma atividade industrial ou comercial. Segundo Srivastava e Srivastava (2006), há ao menos três importantes razões para que empresas industriais invistam em logística reversa: construção de imagem corporativa pela preocupação socioambiental; novas fontes de matérias-primas mais baratas; e atendimento à legislação.

Leite (2009) separa os bens de interesse para atividades de logística reversa em: (i) bens de pós-consumo, que são os materiais que sobram após o consumo por parte do cliente final; e (ii) bens de pós-venda, que voltam ao ciclo produtivo antes de chegar ao cliente final, seja por avaria, perda de prazo de validade, ou perda de valor comercial. Em ambos os casos, é possível recuperar parte do valor original do bem (PEREIRA et al., 2012)

Resíduos podem voltar ao ciclo produtivo por diferentes canais (TEIXEIRA e BIDONE, 1999; BEULLENS, 2004; LIMA, 2005; GUIDE e WASSENHOVE, 2001):

Reciclagem: compreende os materiais constituintes dos bens retornados que possam ser extraídos e separados industrialmente, transformando-se em matérias-primas secundárias para novos produtos na mesma ou em outra indústria (p. ex.: papéis, vidros, metais);

- Reaproveitamento: compreende os bens retornados que ainda possuam vida útil ou possam ser adaptados ou transformados, podendo ser revendidos ou reaproveitados diversas vezes, sempre próximos da forma original (p. ex.: eletrodomésticos, veículos, equipamentos);

- Remanufatura: compreende os bens que, por defeito técnico ou estético ou perda de valor comercial, voltam ou do próprio controle de qualidade da empresa ou até mesmo do varejo para a manufatura, a fim de serem reconstruídos ( $p$. ex.: eletrodomésticos, móveis, calçados, computadores); e

- Rejeitos: caso nenhuma das alternativas acima seja possível, ao menos uma disposição final adequada deve ser provida, seja em aterros, seja em incineradores.

Especificamente no setor de alimentos, 
empresas fornecedoras preocupam-se em recolher itens fora do prazo de validade, para evitar casos de contaminação ou intoxicação alimentar e proteger a marca contra exposições negativas (CHAVES, 2005). Em várias indústrias, é possível observar relações de colaboração e troca de conhecimento entre empresas na operação da cadeia reversa, envolvendo os canais de retorno (RODRIGUES e SELLITTO, 2008).

\subsection{Papel e importância das cooperativas nas cadeias reversas}

Associações ou cooperativas de catadores de resíduos podem desempenhar um papel em cadeias logísticas reversas (AQUINO et al., 2009). Cabe às cooperativas estabelecer uma ligação entre os canais de oferta de materiais recuperáveis e os canais de reaproveitamento. As cooperativas separam e dão algum volume à operação de catação, $o$ que resulta em especificidade, aumento de oferta e redução de custo do material ofertado pela cadeia reversa (GONÇALVES-DIAS e TEODÓSIO, 2006).

A Tabela 1 apresenta os percentuais e os valores absolutos em toneladas de RSU recolhidos no ano de 2012 no Brasil.

Tabela 1: Principais tipos de materiais no total de RSU coletados no Brasil em 2012

\begin{tabular}{rcl}
\hline tipo de material & percentual & tonelagem \\
\hline Metais & $2,9 \%$ & 1.640 .294 \\
papel, papelão, & $13,1 \%$ & 7.409 .603 \\
tetrapak & $13,5 \%$ & 7.635 .851 \\
plástico & $2,4 \%$ & 1.357 .484 \\
vidro & $51,4 \%$ & 29.072 .794 \\
matéria orgânica & $16,7 \%$ & 9.445 .830 \\
outros & $100,0 \%$ & 56.561 .856 \\
\hline
\end{tabular}

Fonte: ABELPRE (2013)

Observa-se a expressiva participação, tanto em percentual como em tonelagem, de materiais recuperáveis (quase vinte milhões de toneladas em um ano). Dado este montante, a contribuição que cooperativas de reciclagem podem oferecer é expressiva, pois parte desta oferta pode não estar sendo direcionada a cadeias reversas e seu valor remanescente desperdiçado.

As cooperativas recebem materiais recuperáveis em grande escala do poder público, por meio da coleta seletiva. Também recebem materiais em menor escala de catadores autônomos regulares e de convênios com entidades de bairro, instituições de ensino e religiosas, supermercados e iniciativas individuais. Por fim, as cooperativas também podem receber materiais de catadores eventuais ou de associações de menor porte, de modo a aumentar sua escala de produção (CHAVES e BATALHA, 2006).

As cooperativas recebem os vários tipos de materiais, usualmente misturados, e procedem a uma separação inicial, entre recuperáveis e orgânicos que porventura permaneçam misturados. Seguem prensagem, picote, enfardamento, armazenamento, e expedição para compradores, que repassam ao usuário final do resíduo. Suas atividades não se limitam ao processamento e venda de materiais para indústrias. A cooperativa também destina uma parte dos materiais recuperados para artesanato, mobiliário e objetos decorativos. Também não é incomum o envolvimento de catadores e familiares em projetos sociais, ambientais e educacionais (SOUZA et al., 2012).

Cooperativas podem contribuir para o aumento do volume de RSU que não são destinados a aterros, para o aumento da vida útil dos aterros existentes, para a redução de descartes irregulares, para a redução na proliferação de vetores de doenças, principalmente os associados a vazadouros, para o aumento do valor recuperado de bens retornados, para redução no custo de abastecimento de matérias-primas para a indústria, para o aumento da eficiência energética de processos de fabricação, entre outros benefícios (SANTOS, 2012). Ademais, as cooperativas contribuem decisivamente para a consolidação de programas de logística reversa de empresas que recuperam produtos (SOUZA et al., 2012). Também contribuem para a redução da situação de vulnerabilidade de comunidades carentes, pois proporcionam opção permanente de emprego e renda a franjas carentes da população (MAZZEI e CRUBELLATE, 2007).

Pedroso e Zwicker (2007) destacam que iniciativas ambientalmente amigáveis devem trazer retornos positivos para empresas e comunidades, tanto intangíveis quanto tangíveis. No caso das cooperativas, os retornos são tangíveis: ganhos econômicos para as empresas que recebem recuperáveis, ganhos ambientais para as comunidades, pela redução de pressão sobre a destinação final, e ganhos sociais, pela redução de vulnerabilidade de comunidades (SOUZA et al., 2012). 


\section{METODOLOGIA}

A abordagem de pesquisa é qualitativa e exploratória, pois não foram feitos modelos matemáticos de apoio à pesquisa e este foi o primeiro contato com o objeto de estudo, as cooperativas. O método do estudo de caso foi escolhido devido à complexidade do objeto e à diversidade presente no fenômeno, o que dificulta o uso de levantamentos ou experimentos (GIL, 2010). A abordagem qualitativa é indicada para o caso, pois os fatos levantados serviram de base para a geração de hipóteses a testar em outros estudos (ROESCH, 1996; KÖCHE, 1997).

Os instrumentos e técnicas utilizados na coleta de dados foram: pesquisa em relatórios fornecidos pelas cooperativas; entrevistas semiestruturadas com os presidentes no cargo em $2012 \mathrm{e}$ observação não-participante. As entrevistas foram previamente agendadas, com duração média de 45 minutos, foram gravadas e transcritas para garantia da qualidade na interpretação dos dados. As entrevistas basearam-se no protocolo de pesquisa do Quadro 1.

\begin{tabular}{ll}
\multicolumn{2}{c}{ Quadro 1: Protocolo de pesquisa } \\
\hline Tema & Desenvolvimento \\
\hline $\begin{array}{l}\text { Histórico da } \\
\text { cooperativa }\end{array}$ & $\begin{array}{l}\text { Fale um pouco a respeito do início } \\
\text { das atividades, das motivações } \\
\text { iniciais para a criação da } \\
\text { cooperativa, dos estímulos recebidos } \\
\text { para as atividades iniciais }\end{array}$ \\
$\begin{array}{l}\text { Operação da } \\
\text { cooperativa }\end{array}$ & $\begin{array}{l}\text { os procedimentos operacionais, } \\
\text { as dificuldades, os principais } \\
\text { resultados, }\end{array}$ \\
Remuneração & $\begin{array}{l}\text { Qual o critério para remuneração } \\
\text { dos cooperados? Qual é, em média, } \\
\text { a remuneração de um cooperado? }\end{array}$ \\
$\begin{array}{l}\text { Relacionamento } \\
\text { como o poder } \\
\text { público e } \\
\text { entidades }\end{array}$ & $\begin{array}{l}\text { relacionado com a prefeitura e } \\
\text { outras entidades públicas e privadas? } \\
\text { Qual a imagem que a cooperativa }\end{array}$ \\
acha que tem junto à comunidade? \\
Objetivos futuros
\end{tabular}

\section{RESULTADOS}

\section{I Análise de relatórios}

Os resultados da análise dos relatórios e os extratos das entrevistas foram transcritos e organizados, segundo os tópicos pesquisados.
Inicia-se pela análise de relatórios disponibilizados pelas cooperativas, de confecção própria e também produzidos pela Secretaria Municipal do Meio Ambiente - SEMMAM de São Leopoldo.

O município opera atualmente sete tipos de coletas: domiciliar, seletiva, de óleo de fritura (junto com a coleta seletiva, destinado à fabricação de sabão e detergente), de animais mortos em via pública (por demanda), de resíduos sem identificação (entregues nos entrepostos mantidos pela prefeitura), de resíduos especiais (lâmpadas, pilhas, baterias, e medicamentos vencidos) e de resíduos de difícil acesso (arroios, viadutos e canteiros centrais).

Para este artigo interessam a coleta seletiva e a domiciliar. O Programa Municipal de Coleta Seletiva está implantado desde o dia $1^{\circ}$ de novembro de 2005 e é de responsabilidade da SEMMAM. A segregação dos resíduos sólidos na origem é de responsabilidade de toda a população, cabendo aos moradores a adequada separação entre resíduos aproveitáveis e resíduos orgânicos. As cooperativas de reciclagem recebem cerca de 220 toneladas por mês de material retornável, mas apenas cerca de $40 \%$ retornam à indústria. O restante é desperdiçado por mistura com resíduo orgânico, devido à segregação precária nas residências.

Em 2011, foram recolhidas 45 mil toneladas totais na coleta domiciliar e 3 mil toneladas na coleta seletiva. Deste montante, $60 \%$ é resíduo orgânico (28,8 mil toneladas), 30\% resíduo retornável (14,4 mil toneladas) e 10\% não foi identificado (4,8 mil toneladas). Das 48 mil toneladas de resíduo sólido recolhidas em 2011, 14,4 mil toneladas eram retornáveis, porém apenas 5,76 mil toneladas foram recicladas. Ao todo, cerca de 90 empresas comerciais e industriais destinam seus resíduos diretamente às seis cooperativas existentes no município. Atualmente, os preços por quilo auferidos pelas cooperativas são: plástico a $\mathrm{R} \$ 0,60$; papéis e papelão em média a $\mathrm{R} \$$ 0,18 ; metais em média a $R \$ 2,50$; vidro em média a $R \$ 1,00$. As cooperativas do município geram benefícios para cerca de 240 famílias.

\subsection{Histórico das Cooperativas}

A cooperativa A iniciou suas atividades em 2005, em bairro da zona sul da cidade, atuando em condições inadequadas de higiene e segurança. O galpão era próprio, porém pequeno e em situação precária de segurança. A partir de 2009, passou a usar um prédio de $330 \mathrm{~m}^{2}$ alugado pela prefeitura e a receber subsídio financeiro da prefeitura para o custeio de operação e manutenção do galpão. A 
cooperativa B surgiu em 1998 e atua desde 2002 junto ao Aterro Sanitário Municipal, conhecido como Usina de Reciclagem e Compostagem de Resíduos Domésticos de São Leopoldo. A partir de 1999, passou a receber materiais das cidades vizinhas de Portão e Sapucaia do Sul.

Ambas organizaram-se sob a forma de redes de cooperados autogestionadas. A motivação para a atividade em grupo (ou rede) era garantir as quantidades, a qualidade e a frequência de entregas exigidas pela indústria. Trabalhando em rede, e mantendo os parâmetros de atendimento citados, as cooperativas puderam garantir sua sobrevivência de longo prazo e obter melhores condições de venda para o produto final, repassado tanto a intermediários como a empresas consumidoras de matérias-primas. Apesar de eventualmente receberem materiais de catadores autônomos, os carrinheiros, ambas as cooperativas estão organizadas para receber material oriundo da coleta seletiva da cidade e de convênios firmes com instituições de ensino, religiosas e com supermercados da região. Ambas se organizaram nos seguintes processos industriais: recebimento; triagem (recicláveis e rejeitos orgânicos); separação dos recicláveis em metal, plástico, vidro e papel; prensagem (menos vidro); balança; armazenagem; e expedição.

A Cooperativa A localiza-se em bairro residencial, com infraestrutura precária para o trânsito de veículos pesados. A cooperativa recebe os resíduos diretamente dos veículos de coleta seletiva e de veículos leves que recolhem materiais coletados nas instituições conveniadas. $\mathrm{O}$ processo se inicia com uma mesa para seleção dos principais tipos de resíduos: papel, plástico, vidro e metal. Além disso, faz separação específica de embalagens TetraPak. Oito mulheres fazem a seleção na mesa, sendo cada uma responsável pela seleção de um tipo de resíduo. Após a seleção, vêm os processos de embalagem e prensagem, com mais cinco pessoas. Ao todo, treze pessoas executam a tarefa diariamente, sendo os processos que exigem mais força, como deslocamento de fardos ou prensagem, designados a homens. Ao fim, os resíduos são separados em fardos de até $250 \mathrm{~kg}$, formando blocos para venda. A carga horária de trabalho é de seis horas por dia. Como os resíduos são oriundos da coleta seletiva, quase todo o material recebido é destinado para venda. A produção diária é de cerca de 3 toneladas de resíduo processado.

A cooperativa B se localiza junto ao aterro municipal, portanto recebe os resíduos diretamente de caminhões de coleta urbana. Os caminhões de coleta domiciliar passam três vezes por semana em cada bairro, de segunda-feira a sábado. Os resíduos são despejados em uma esteira transportadora. $\mathrm{Na}$ primeira parte da esteira, dois operadores acomodam os resíduos no equipamento, trabalhando com equipamentos de proteção individual (EPI) adequados (luvas, avental, botinas e óculos). Ao longo da esteira, os demais cooperados (que também trabalham com EPI adequado) separam o material conforme o tipo de resíduo: papel, papelão, plástico, vidro, e metal. Os resíduos orgânicos não são removidos da esteira e ao fim caem em contenedores e são destinados ao aterro.

Os materiais separados são selecionados em uma segunda triagem (por exemplo: os plásticos são separados em duros e de embalagens; os papéis em brancos e coloridos). Após a segunda triagem, os materiais já separados em tipos são encaminhados para prensagem e finalização de bloco para venda. Adicionalmente, a cooperativa abastece artesãos de um atelier de fabricação de cestas com papel jornal e outros objetos decorativos. Em média, de todo o resíduo recebido, apenas $8 \%$ pode ser aproveitado para retorno. A cooperativa opera em dois turnos de trabalho: das 6:00 às 14:00 e das 14:00 às 22:00. Nos sábado, também há expediente, em equipes intercaladas. Dos $40 \%$ de resíduo seco que retornou para a indústria em 2011, 18\%, ou seja, quase a metade, foi processada por B. As demais cooperativas da cidade reciclaram juntas os outros $22 \%$. A produção diária é de cerca de nove toneladas de resíduo processado.

A renda mensal dos cerca de trinta cooperados da cooperativa $\mathrm{A}$, em 2012 , oscilou entre $\mathrm{R} \$ 600,00$ e $\mathrm{R} \$ 700,00$ por cooperado. A renda mensal dos cooperados da cooperativa B, cerca de 130 , em 2012 , oscilou entre $\mathrm{R} \$ 500,00$ e $\mathrm{R} \$$ 550,00 por cooperado. Em ambos os casos, todo o lucro auferido pela cooperativa foi dividido em partes iguais entre os cooperados.

Quanto ao relacionamento com outras entidades, a cooperativa A recebe subsídio mensal da prefeitura desde 2009, reajustado periodicamente. O reajuste mais recente foi em 2013. O aluguel do galpão tem sido pago pela prefeitura desde o início das operações. Mesmo assim, a estrutura é pouco eficiente para a atividade. As demais despesas de infraestrutura, tais como energia e saneamento, são pagas com recursos originados da operação da cooperativa. A cooperativa conta com convênios com instituições de ensino e religiosas e empresas comerciais da região, que separam resíduos e entregam na cooperativa. A coleta seletiva do município também é entregue na cooperativa. A 
cooperativa tem problemas de relacionamento com a vizinhança, devido ao fluxo de veículos e o mau cheiro originado da atividade. As instalações da cooperativa B são mantidas pela empresa de engenharia sanitária que faz a coleta de resíduo domiciliar, em área pertencente ao município. Desde a fundação, conta com apoio técnico e de gestão da União Protetora do Ambiente Natural (UPAN), uma organização não-governamental ambientalista. $\mathrm{Na}$ fundação, solicitou apoio da prefeitura para a construção do galpão. Em 2000, a prefeitura cedeu terreno de $650 \mathrm{~m} 2$ e elaborou o projeto para a construção de galpão industrial de $400 \mathrm{~m} 2$, junto ao aterro sanitário. Periodicamente, por iniciativa própria, os cooperados realizam mutirões de limpeza urbana nas ruas da vila lindeira à cooperativa.

Quanto aos objetivos futuros, a cooperativa A depende diretamente de subsídios do poder público municipal e está localizada em bairro residencial, com problemas para sua operação. Portanto, é importante regularizar suas instalações. Algumas empresas, tais como Banco do Brasil, Stihl e Vonpar mostraram-se interessadas em contribuir para a construção de novas instalações. No entanto, para poder receber este incentivo, a cooperativa precisará desenvolver uma estrutura gerencial ainda inexistente. A cooperativa B também depende do poder público, mas em escala bem menor do que A. A cooperativa B está em estágio mais alto de maturidade, a ponto de já pensar em normalizações de segurança (PPRA, PCMCO, PPCI) para prevenir causas trabalhistas de antigos cooperados. B estuda a viabilidade de estender suas atividades para o aproveitamento de resíduos orgânicos com estações de compostagem e de vender direto aos compradores de retornáveis, evitando intermediários e aumentando a margem de lucro da venda.

\section{DISCUSSÃO}

A discussão ocorre em quatro eixos principais: infraestrutura, resultado para os cooperados, crescimento, e importância das cooperativas na cadeia reversa.

\section{I Infraestrutura}

Quanto à infraestrutura, a Cooperativa $\mathrm{B}$ é muito superior à Cooperativa $\mathrm{A}$, tanto pela localização próxima ao aterro, como em equipamentos e proteção a trabalhadores e máquinas. Suas instalações têm capacidade de atender ple- namente à demanda diária. O galpão foi projetado e construído especificamente para a atividade, com espaços destinados aos diversos estágios do processo. A Cooperativa A enfrenta problemas internos, tais como falta de piso apropriado para o escoamento do chorume, espaço de espera de resíduos, e pé direito insuficiente para movimentação segura de fardos. A proteção contra sinistros é inadequada, tanto que um incêndio destruiu quase $50 \%$ do galpão original. Devido ao local inadequado, a cooperativa responde atualmente por dois processos judiciais.

\subsection{Resultado para os cooperados}

Quanto ao resultado para os cooperados, apesar da cooperativa B ser maior e ter uma estrutura mais adequada, a cooperativa A é mais rentável, alcançando renda maior aos cooperados e operando em horário menor. Percebeu-se também que a cooperativa $\mathrm{A}$, mesmo sendo menor, tem uma preocupação maior com o conhecimento e satisfação dos seus cooperados, proporcionando participação em grupos de discussões, fóruns de questões ambientais ou movimentos que possam contribuir para uma vida melhor das famílias. Ambas as cooperativas optam por cooperados acima de 40 anos, principalmente donas de casa, pois julgam que estas são mais comprometidas e tendem a permanecer na cooperativa por mais tempo. Ambas as cooperativas possuem uma típica linha de produção, com pessoas destinadas a cada atividade, com o objetivo de otimizar o tempo, o espaço e com fácil acesso a todas as ferramentas. A cooperativa A observa amadurecimento quando compara o momento atual com o início das atividades. Antes, todos coletavam e selecionavam todos os tipos de materiais, ocupando mal o pequeno espaço que eles têm com postos de trabalhos desnecessários.

A cooperativa A recebe apenas o lixo oriundo da coleta seletiva, o que produz ambiente de trabalho mais limpo e livre de pragas ou doenças, além da facilidade de conseguir vender quase $100 \%$ do que é recebido. A cooperativa $B$ tem a desvantagem de receber o resíduo total do Município, o que inclui o resíduo orgânico, que inviabiliza parte do reaproveitamento. Como não há compostagem para o lixo orgânico separado, este não gera renda. Em B, apenas cerca de 8\% do resíduo recebido é recuperado para venda.

\subsection{Crescimento}

A cooperativa A enfrenta a necessidade de mudar de local, para uma área maior e não 
residencial. Mesmo tendo recebido oferta de patrocínio para a mudança, cabe a A encontrar local, o que demanda uma estrutura gerencial inexistente. $\mathrm{B}$ não tem problemas de crescimento físico. No entanto, como a renda dos cooperados é mais baixa do que em A, deve ampliar seus negócios, incluindo compostagem e venda direta. Ambas as cooperativas relataram preocupação com o crescimento observado na geração de resíduo, que não é acompanhado pela quantidade de resíduo seco coletado. Ou seja, ainda é pequena a conscientização da população da cidade sobre a importância da separação doméstica dos resíduos.

\subsection{Importância nas cadeias logísticas reversas}

Ambas as cooperativas recebem resíduos do poder público. A recebe apenas a coleta seletiva, enquanto $B$ recebe a coleta domiciliar completa e segrega a parte retornável. Portanto, ambas as cooperativas desempenham um papel a jusante das cadeias logísticas de suprimento: um papel tipicamente de pós-consumo. A produção de ambas as cooperativas é vendida para intermediários, que dão maior escala aos retornáveis, ou, em alguns poucos casos, para empresas de pequeno porte, que as usa como matéria-prima. Portanto, as cooperativas também desempenham um papel de abastecedores da indústria.

Em relação ao abastecimento da indústria, Pokharel e Mutha (2009) chamaram a atenção especificamente sobre a importância de unidades coletoras (os autores chamam de collection centres) para a cadeia logística reversa. Adaptando o conceito dos autores citados para a realidade local, chega-se às cooperativas de catadores. Segundo os autores, tais unidades deveriam ser cooptadas e apoiadas por manufaturadores por meio de contratos de longo prazo, de modo a garantir suprimento barato de matéria-prima. O que se observou nos casos estudados é que a venda ocorre para intermediários, que dão mais escala e tornam mais produtiva a operação, mas que reduzem em até $50 \%$ a margem de lucro das cooperativas. Caso houvesse a venda direta, possivelmente a indústria também seria beneficiada, pois o preço final do insumo também cairia, prevalecendo a lógica do encurtamento das cadeias de suprimentos.

Em síntese, o papel das cooperativas de catadores nas cadeias logísticas reversas é de receber e reprocessar os resíduos pós-consumo, recuperar parte do valor destes resíduos e fornecer matéria- prima para novo abastecimento da indústria. De modo geral, não foi observada maior participação das cooperativas no retorno de bens pós-venda.
Para tanto, a cooperativa deveria ter estrutura para desmonte de equipamentos ou bens, eventuais reparos e remanufatura, o que não foi observado e nem foi apontado como perspectiva futura.

A Figura 1 mostra o papel e a posição das cooperativas nas cadeias de retorno.

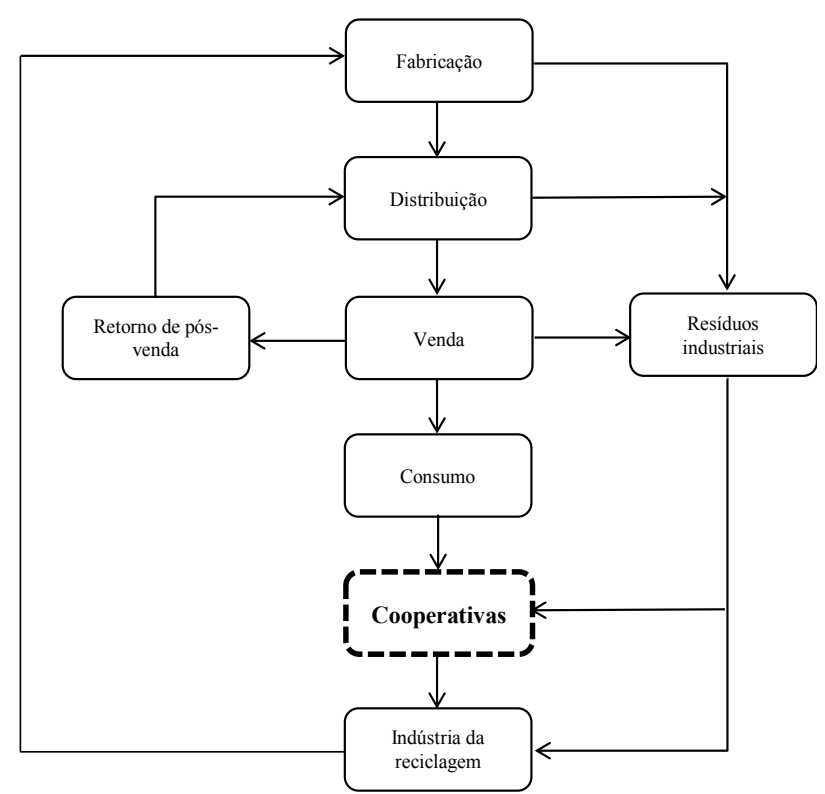

Figura 01 - Posição das cooperativas nas cadeias logísticas (Fonte: autoria própria)

\section{CONCLUSÕES}

O estudo apontou que uma das cooperativas recebe apenas materiais já selecionados pela coleta seletiva municipal, enquanto que a outra cooperativa recebe materiais gerais originados da coleta domiciliar. O estudo também mostrou que uma das cooperativas é mais bem estruturada e localizada do que a outra. No entanto, a cooperativa mais bem estruturada alcança menos resultado financeiro, pois a coleta domiciliar rende menos do que a coleta seletiva. No entanto, para sua sobrevivência, ambas as cooperativas precisam de apoio externo, seja do poder público, seja da empresa de engenharia sanitária que faz a coleta municipal. O atual modelo de negócios não é suficiente para conferir plena autonomia às cooperativas. Para tanto, mais produtividade é necessária, o que pode incluir aproveitamento do resíduo orgânico e venda direta à indústria, evitando intermediações.

Resultados sociais e ambientais da ação das cooperativas também foram observados. Social- 
mente, cerca de 240 famílias de baixa renda são beneficiadas pela ação das duas cooperativas, pois estas oferecem alternativa de emprego e renda. Ambientalmente, as cooperativas têm contribuído para a extensão da vida útil do aterro sanitário da cidade, pois sua ação tem evitado que cerca de doze toneladas diárias sejam destinadas ao mesmo.

A pergunta de pesquisa foi respondida: 0 papel das cooperativas de reciclagem nas cadeias logísticas reversas é o de receber e processar resíduos pós-consumo e resíduos industriais e abastecer a indústria com matéria-prima recuperada. Adicionalmente, é papel social das cooperativas contribuir para a redução da vulnerabilidade de famílias de baixa renda e é papel ambiental contribuir para o aumento da vida útil dos aterros sanitários, poupando a natureza de receber uma parte dos resíduos gerados pela atividade antrópica urbana. A principal dificuldade encontrada na pesquisa foi a pouca organização administrativa nas cooperativas, o que exigiu dos pesquisadores trabalho maior do que o esperado para a busca de dados relevantes para o objetivo.

Para estudos futuros, sugere-se que as demais quatro cooperativas da cidade sejam estudadas, completando o panorama do município. Também sugere-se um estudo quantitativo, analisando as séries temporais dos volumes recebidos e processados pelas cooperativas, o que deverá incluir dados específicos sobre os vários tipos de resíduos separados.

\section{REFERÊNCIAS}

ABRELPE. Associação Brasileira de Empresas de Limpeza Pública e Resíduos Especiais. Panorama de Resíduos Sólidos no Brasil. 2012. São Paulo. Disponível em http://www.abrelpe.org.br/Panorama/ panorama2012.pdf, acesso em out/2013.

ADLMAIER, D.; SELLITTO, M. Embalagens retornáveis para transporte de bens manufaturados: um estudo de caso em logística reversa. Produção, v.17, n.2, p.395-406, 2007.

ANDRADE, R.; FONSECA, C.; MATTOS, K. Geração e destino dos resíduos eletrônicos de informática nas instituições de ensino superior de Natal-RN. HOLOS, v.26, n.2, p.100-112, 2010.

AQUINO, I.; CASTILHO JR., A.; PIRES, T. A organização em rede dos catadores de materiais recicláveis na cadeia produtiva reversa de pós-consumo da região da grande Florianópolis: uma alternativa de agregação de valor. Gestão \& Produção, v.16, n.1, p.15-24, 2009.

BALLOU, R. Gerenciamento da cadeia de suprimentos: planejamento, organização e logística empresarial. Porto Alegre: Bookmann, 2005.

BARKER, T.; ZABINSKY, Z. A multicriteria decision making model for reverse logistics using analytical hierarchy process. Omega, v.39, n.5, p. 558-573, 2011.

BELTRAME, T.; LHAMBY, A.; NUNES, A.; SCHMIDT, A. Diagnóstico dos resíduos gerados e viabilidade de implantação da coleta seletiva em um município do Rio Grande do Sul/RS. Anais do III Congresso Brasileiro de Gestão Ambiental. Goiânia: 2012

BEULLENS, P. Reverse logistics in effective recovery of products from waste materials. Reviews in Environmental Science \& Bio/Technology. (2004) 3:4 283-306

BORCHARDT, M.; POLTOSI, L.; SELLITTO, M.; PEREIRA, G. Considerações sobre ecodesign: um estudo de caso na indústria eletrônica automotiva. Ambiente \& Sociedade, v.11, n.2, p.341-353, 2008.

CELERE, M.; OLIVEIRA, A.; TREVILATO, T.; MUÑOZ, S. Metais presentes no chorume coletado no aterro sanitário de Ribeirão Preto, São Paulo, Brasil, e sua relevância para saúde pública. Cadernos de Saúde Pública, v.23, n.4, p.939-947, 2007.

CEMPRE - COMPROMISSO EMPRESARIAL PARA A RECICLAGEM. Pesquisa Ciclosoft: Radiografando a coleta seletiva. São Paulo: CEMPRE, 2008.

CHAVES, G. Diagnóstico da logística reversa na cadeia de suprimentos de alimentos processados no oeste paranaense. Dissertação (Mestrado em Agronegócios). Universidade Estadual do Oeste do Paraná, Toledo: 2005.

CHAVES, G.; BATALHA, M. Os consumidores valorizam a coleta de embalagens recicláveis? Um estudo de caso da logística reversa em uma rede de hipermercados. Gestão \& Produção, v.13, n.3, p.423-434, 2006.

COSTA, L.; MAGALHÃES, F; CARMO, D.; 
NASSAR, C; PEREIRA, C.; GONÇALVES, C.; MENEZES, A.; WILKER, W.; OLIVEIRA, A.; MARIANO, F.; NASCIMENTO, L.; VENEROSO, F.; CAIS, T.; SERVIDONE, L.; BATISTA, C.; ROJAS, K. Caracterização e Percepção Ambiental Dos Resíduos Sólidos Urbanos nas Diferentes Classes Sociais no Município de Alfenas-MG. Revista em Agronegócio e Meio Ambiente, v.5, n.2, p.25-49, 2012.

FRÉSCA, F. Estudo da geração de resíduos sólidos domiciliares no município de São Carlos, SP, a partir da caracterização física. Dissertação (Mestrado em Engenharia Ambiental). USP. São Carlos: 2007.

GEORG, P.; MITSUEDA, N.; LOPES, J. Sensibilidade ambiental: consumo e separação de materiais recicláveis em um bairro de Maringá-PR. Revista em Agronegócios e Meio Ambiente, v.2, n.2, p.139-154, 2009.

GIL, A. Como Elaborar Projetos de Pesquisa. São Paulo: Atlas, 2010.

GONÇALVES-DIAS, S. Há vida após a morte: um (re) pensar estratégico para o fim da vida das embalagens. Gestão \& Produção, v.13, n.3, p.463-474, 2006.

GONÇALVES-DIAS, S.; TEODÓSIO, A. Estrutura da cadeia reversa:" caminhos" e" descaminhos" da embalagem PET. Produção, v.16, n.3, p.429-441, 2006.

GUIDE, V.; WASSENHOVE, L. Managing product returns for remanufacturing. Production and Operations Management, v.10, n.2, p.142-155, 2001.

HIRAMA, A.; SILVA, S. Coleta seletiva de lixo: uma análise da experiência do município de Maringá-PR. Revista Tecnológica, v.18, n.1, p.11-24, 2009.

IBGE. INSTITUTO BRASILEIRO DE GEOGRAFIA E ESTATÍSTICA. Pesquisa Nacional de Saneamento Básico. 2010. Disponível em http:// www.brasil.gov.br/governo/2010/08/ibge-divulga-pesquisa-nacional-de-saneamento-basico-1. Acesso em out/2013.

JACOBI, P. Educação ambiental, cidadania e sustentabilidade. Cadernos de Pesquisa, n.118, v.2, p.189205, 2003.
KOCHE, J. Fundamentos de Metodologia Científica. 14. ed. Petrópolis: Vozes, 1997.

LEITE, C.; BERNARDES, R.; OLIVEIRA, S. Método Walkley- Black na determinação da matéria orgânica em solos contaminados por chorume. Revista Brasileira de Engenharia Agrícola e Ambiental, v.8, n.1, p.111-115, 2004.

LEITE, M. A taxa de coleta de resíduos sólidos domiciliares: uma análise crítica. Dissertação (Mestrado em Engenharia Civil). Escola de Engenharia de São Carlos da USP. São Carlos: 2006.

LEITE, P. Logística Reversa: Meio Ambiente e competitividade. São Paulo: Prentice Hall, 2009

LIMA, J. Sistemas Integrados de Destinação Final de Resíduos Sólidos Urbanos, ABES, Paraíba, 2005.

MACHADO, P. Princípios da política nacional de resíduos sólidos. Revista do Tribunal Regional Federal da 1 ${ }^{a}$ Região, v. 24, n. 7, p. 25-33, 2012.

MAZZEI, B.; CRUBELLATE, J. Autogestão em empreendimentos econômicos solidários: um estudo comparativo de casos em cooperativas de reciclagem de Maringá - PR. Anais do ENANPAD. Rio de Janeiro: Anpad, 2007.

MESQUITA JÚNIOR, J. Mecanismo de desenvolvimento limpo aplicado a resíduos sólidos: Gestão integrada de resíduos sólidos. Brasilia: Ministério do Meio-Ambiente e Ministério das Cidades, 2007.

MONTEIRO, J.; ZVEIBIL, V. Manual de Gerenciamento Integrado de resíduos sólidos. Rio de Janeiro: IBAM, 2001.

MORAES, F. ACAMART: autogestão e participação na cadeia produtiva. é possível? Revista Geográfica de América Central, v.2, n. 47, p.1-14, 2011.

MORAES, F.; SILVA, K.; LEAL, A. Coleta Seletiva no Município de Martinópolis-SP. Anais do VI Seminário Latino Americano e II Seminário Ibero Americano de Geografia Física. Martinópolis: 2006.

NAIME, R.; ABREU, E.; ATTILIO, D. Proposição para o Gerenciamento de Resíduos da Construção e Demolição de Cuiabá. Revista Eletrônica em Gestão, Educação e Tecnologia Ambiental, v.15, n.15, p.2902-2911, 2013. 
OLIVEIRA, F.; ALVES, M.; OLIVEIRA, C. Favorabilidade de áreas para implantação de aterros controlados no município de Campos dos Goytacazes/RJ utilizando sistema de informação geográfica. Revista Brasileira de Cartografia, v.64, n.1, p.33-44, 2012.

PEDROSO, M.; ZWICKER, R. Sustentabilidade na cadeia reversa de suprimentos: um estudo de caso do Projeto Plasma. RAUSP, v.42, n.4, p.414-430, 2007.

PEREIRA NETO, T. A Política Nacional de Resíduos Sólidos: Os Reflexos nas Cooperativas de Catadores e a Logística Reversa. Diálogo, v.18, n.1, p. $77-96,2011$.

PEREIRA, A.; BOECHAT, C.; TADEU, H.; JERSONE, T. Logística Reversa e Sustentabilidade. São Paulo: Cengage Learning, 2012.

PFEIFFER, S. Subsídios para a ponderação de fatores ambientais na localização de aterros de resíduos sólidos, utilizando o Sistema de Informações Geográficas. 2001. Tese (Doutorado em Engenharia Civil) - Escola de Engenharia de São Carlos, Universidade de São Paulo, São Carlos/SP, 2001.

POKHAREL, S.; MUTHA, A. Perspectives in reverse logistics: A review. Resources, Conservation and Recycling, v.53, n.2, p.175-182, 2009.

ROCHA, D. Uma análise da coleta seletiva em Teixeira de Freitas-Bahia. Caminhos de Geografia, v.13, n.44, p.140-155, 2012.

RODRIGUES, D.; SELLITTO, M. Práticas logísticas colaborativas: o caso de uma cadeia de suprimentos da indústria automobilística. RAUSP, v.43, n.1, p.97-11, 2008.

ROESCH, S. Projeto de Estágio do Curso de Administração: guias para pesquisa, projeto, estágio e trabalhos de conclusão de curso. São Paulo: Atlas, 1996.

ROGERS, D.; MELAMEDI, B.; LEMBKES, R. Modeling and Analysis of Reverse Logistics, Journal of Business Logistics, v.33, n.2, p.107-117, 2012.

SANTIAGO, L.; DIAS, S. Matriz de indicadores de sustentabilidade para a gestão de resíduos sólidos urbanos. Engenharia Sanitária e Ambiental, v.17, n.2, p.203-212, 2012.

SANTOS, J. A logística reversa como ferramenta para a sustentabilidade: um estudo sobre a importância das cooperativas de reciclagem na gestão dos resíduos sólidos urbanos. REUNA, v.17, n.2, p.81-96, 2012.

SARKIS, J.; HELMS, M.; HERVANI, A., Reverse Logistics and Social Sustainability. Corporate Social Responsibility and Environmental Management, v.17, n.6, p.337-354, 2010.

SOUZA, M.; PAULA, M.; SOUZA-PINTO, H. papel das cooperativas de reciclagem nos canais reversos pós-consumo. Revista de Administração de Empresas, v.52, n.2, p.246-262, 2012.

SOUZA, O.; FEDERIZZI, M.; COELHO, B.; WAGNER, T.; WISBECK, E. Biodegradação de resíduos lignocelulósicos gerados na bananicultura e sua valorização para a produção de biogás. Revista Brasileira de Engenharia Agrícola e Ambiental, v.14, n. 4, p.438-443, 2010.

SRIVASTAVA, S.; SRIVASTAVA, R. Managing product returns for reverse logistics. International Journal of Physical Distribution and Logistics Management, v.36, n.7, p.524-546, 2006.

TEIXEIRA, E.; BIDONE, F. Metodologias e técnicas de minimização, reciclagem e reutilização de resíduos sólidos urbanos. Rio de Janeiro: ABES - Associação Brasileira de Engenharia Sanitária e Ambiental, 1999.

VILLARES, M. Gestão Ambiental e Destinação Final de Resíduos Sólidos Urbanos no Município de Miguel Pereira - RJ: um estudo de caso. Dissertação (Mestrado em Engenharia Ambiental). Faculdade de Engenharia. UERJ. Rio de Janeiro: 2009. 